\title{
Occupational health and safety risk assessment in the domain of Industry 4.0
}

\author{
Aylin Adem $^{1}$ (D) Erman Çakit $^{1} \cdot$ Metin Dağdeviren $^{1}$
}

Received: 29 October 2019 / Accepted: 23 April 2020 / Published online: 28 April 2020

(c) Springer Nature Switzerland AG 2020

\begin{abstract}
The objectives of this study were three-fold: (i) to investigate new occupational health and safety risks that may arise with the integration of Industry 4.0 in production environments; (ii) to identify and group these risks into various categories; and (iii) to prioritize these groups. With this prioritization, a number of recommendations will be made to take into account new risk groups that may arise during the reorganizing of production environments according to Industry 4.0. This study used the Hesitant Fuzzy Analytic Hierarchy Process prioritization approach to determine the ranking of risks, which arose with the use of Industry 4.0. In this paper, possible occupational health and safety risks of the selected method consisted of eye-related disorders, mental fatigue, disorders stemming from the static working position, exposure to unknown dangerous particles as a result of cooperation with robots, and psychological pressure (stemming from the problems of adaptation to duties that require creativity). According to the results, the two most important risk factors were mental fatigue and psychological pressure. Mental fatigue as the principal risk factor was not unexpected owing to the many encounters between humans and machines. However, with respect to psychological pressure, we were unable interpret the results in the same way as the mental fatigue case. Psychological pressure is a complicated problem, and a more in-depth and detailed investigation is needed.
\end{abstract}

Keywords Industry 4.0 - Occupational health and safety $\cdot$ Risk identify $\cdot$ Hesitant fuzzy AHP

\section{Introduction}

As time passes, traditional machinery workplaces have converted to smart machine workplaces; therefore, interactions among workplace elements also changes. New industries, such as those related to technology, robotics, computerization, and digitalization, can have serious implications for employment status and expertise, and workers and can face new obstacles in managing human-machinery contacts. New technology and its various facets were named "Industry 4.0" in 2011 following the initiation of the digital production project at the Hannover Fair by Germany. Since then it has become widely used with the word "Industry 4.0." Industry 4.0's development phases are summarized by some as "Economy 4.0" and some call it "4th Wave Industrial Revolution," in the context that the "Industry 1.0" referred to the technology created by the Industrial Revolution; "Industry 2.0" implied Fordist Mass Production in the early 1900's, and "Industry 3.0" was a period in which production grew. Industry 4.0 is now "the fourth wave of technological progress" that relates to the integration of development with the "intelligent" digital revolution [1]. Industry 4.0 is some sort of breakthrough point in production environments with concepts such as the Internet of things and robots for the last decade. Industry 4.0 has both positive and negative effects on employees in terms of occupational health and safety. Thanks to Industry 4.0, occupational diseases caused by

Aylin Adem, aylinadem@gazi.edu.tr; Erman Çakit, ecakit@gazi.edu.tr; Metin Dağdeviren, metindag@gazi.edu.tr|'Department of Industrial Engineering, Gazi University, 06570 Ankara, Turkey. 
the use of physical labour force and repetitive actions were prevented. On the other hand, with the increase of human's machine interaction new occupational health and safety risks arose.

In an intelligent working environment, a large number of sensors gather environmental data in real time and personal characteristics can be captured through face recognition systems. Wearable devices are capable of tracking human condition and collecting data (humidity, brightness, noise, etc.), representing the adaptation of the individual setting and ensuring a safe and scientific work/life environment. The intelligent terminal offers insights into the working practices and activities of employees. When employees have unusual activities, they may recall operators by voice or other data and terminate their operations in order to generate a code of conduct command. In addition, the focus of the work of employees has changed, including the transition from information acquisition to intelligibility and information screening to information integration. Physical workload factors include, among others, manual lifting and carrying, repetitive work, work with display screen equipment and other physical strain, such as difficult or static working positions also decreases, but the worker in the design class increases. Several studies have evaluated the positive and negative effects of Industry 4.0 on production or office environment. These studies have concluded that advanced technology complements skilled labor [2-6].

It has been emphasized that technological changes based on skills lead to structural changes in employment and to new threats in occupational health and safety, as demand for skills increases. The use of digital tools to track employees' behavior, productivity and performance can create an atmosphere of workplace ambiguity, privacy invasion, and psychological pressure [7]. In addition, by increasing work-related stress and having negative health effects in the long term, conflict between employees and supervisors as well as among staff could be increased [4, 8].

In the industry 4.0 environment, more new technologies and related possible risks about the implementation of OHS principles will emerge, which is one of the main objectives of this study. This study also aims to identify and group the risks into various categories, and prioritize these groups using multi-criteria decision-making (MCDM) methods. With this prioritization, a number of recommendations will be made to take into account new risk groups that may arise during the reorganizing of production environments according to Industry 4.0. Therefore, in the current, early phase of knowledge on this topic, a precautionary risk management approach should be adopted to achieve a sustainable development of Industry 4.0 innovations. There are several fuzzy linguistic scales, which can be used in the decision-making processes, like triangular fuzzy numbers, Intuitionistic fuzzy numbers, Pythagorean fuzzy numbers, Rough numbers, hesitant fuzzy numbers, etc. [9-11] However, their attributes and necessities are different from each other. The reason why the Hesitant Fuzzy Linguistic Term set (HFLTS) was utilized to evaluate new risk groups is that HFLTS allows to decision-makers to express their opinion about the decision-making process more flexible way [12]. Because it depends on computing with word approach and provides different linguistic phrase decision-maker to evaluate alternatives or criteria. The details of this term set will be explained in Sect. 2. The remainder of the paper is structured is as follows. Section 2 details the methodological steps including Hesitant Fuzzy Analytic Hierarchy Process (AHP). Section 3 addresses the application of Hesitant Fuzzy approach. Section 4 represents the results. Ultimately, in Sects. 5 and 6, respectively, the discussion and conclusions are presented.

\section{Materials and methods}

\subsection{Hesitant fuzzy AHP}

AHP, which is the most preferred technique among the other MCDM techniques, was presented by Saaty in the 1970s [13]. The AHP's logic is based on the linear algebra and pairwise comparisons the elements of the decisionmaking process. AHP expresses a decision-making problem in a hierarchy. The superiority of this technique can be explained as that it can calculate the weights of elements of decision-making problem whether tangible or intangible. As it is a widely known and frequently used method, the details of the calculation step of AHP are not given in this study, and information about the general method is given. So researchers interested in AHP method can refer to $[10,11]$ for more information.

Saaty proposed this method based on a scale, which is termed Saaty's 1-9 scale. However, this scale has been criticized by researchers as not possessing the capacity to handle the fuzziness of the decision-making environments in Industry 4.0. Fuzzy logic is an analysis method that was purposefully developed to incorporate uncertainty into the decision model [14]. To eliminate the aforementioned criticism, researchers began to apply fuzzy logic to MCDM problems, which are under the fuzzy environment $[10,11$, 15]. Moreover, Zadeh's fuzzy logic has been improved and diversified by other researchers $[12,16-18]$. One of the developed fuzzy numbers is the hesitant fuzzy number. Hesitant fuzzy numbers were previously introduced to the MCDM literature by [12]. Since 2012, HFLTS have been integrated into different MCDM techniques [19-22]. In this 
study, we have applied the hesitant fuzzy extension of AHP adapted from [23]. Table 1 represents the linguistic scale used in this study [23]. The explanations of the linguistic expressions are given as follows:

- $\mathrm{ni}=$ no importance

- vli= very low importance

- li=low importance

- $\mathrm{mi}=$ medium importance

- $\mathrm{hi}=$ high importance

- $v h i=$ very high importance

- $a \mathrm{i}=a b s o l u t e$ importance

In addition, the linguistic expressions above, there are conjunction words like "more than", "at least", "at most", etc. With the help of production rules [9], phrases are produced like "more than very high importance", "at least medium importance", etc. The main steps of the method could be described in 5 points, such as: [23]:

1. Take linguistic expressions from experts

2. Utilize arithmetic mean for criteria values to gain optimistic and pessimistic collective preferences

3. Utilize arithmetic mean for each row of collective preferences matrix to obtain linguistic intervals.

4. Compute the midpoints of linguistic intervals.

5. Obtain the weights of criteria by normalizing midpoints.

For a detail explanation of each step please read [23].

Table 1 The scale for linguistic expressions [23]

\begin{tabular}{lllllll}
\hline ni & vli & li & mi & hi & vhi & ai \\
\hline 0 & 1 & 2 & 3 & 4 & 5 & 6 \\
\hline
\end{tabular}

\section{Hesitant fuzzy application in risk prioritization}

Industry 4.0 has a two-way impact on production environments. While some of these effects are positive, others are negative. To illustrate the former positive effects, it can be said that industry 4.0 causes a decrease in quality problems and repetitive actions. For the latter, it can be stated that industry 4.0 facilitates creation of new occupational health and safety problems. We have analyzed the related published papers to determine novel risks about industry 4.0 in terms of OHS. Moreover, experts from industry, who are enthusiastic about Industry 4.0 and its effects on human resources, were interviewed to investigate possible negative consequences of Industry 4.0 on occupational health and safety issues. Occupational health and safety risks used in this study are derived from [24] and listed as follows:

- Eye related disorders (R1).

- Mental fatigue (R2).

- Disorders stemming from the static working position (R3).

- Exposure to unknown dangerous particles as a result of cooperation with robots (R4).

- Psychological pressure (stemming from the problems of adaptation to duties that require creativity) (R5).

The linguistic evaluations of the experts can be seen in Table 2. In this study, two experts were asked to evaluate new risk groups.

After taking linguistic evaluations from the experts, these evaluations were expressed as intervals (please see Table 3) optimistic and pessimistic collective preferences were computed (please see Table 4) via the arithmetic

Table 2 Linguistic evaluations of Expert-1 and Expert-2

\begin{tabular}{|c|c|c|c|c|c|}
\hline & $\mathrm{R} 1$ & $\mathrm{R} 2$ & R3 & R4 & R5 \\
\hline \multicolumn{6}{|c|}{ Expert-1 } \\
\hline R1 & - & $\mathrm{mi}$ & Between mi and hi & at least hi & Between vli and hi \\
\hline $\mathrm{R} 2$ & $\mathrm{mi}$ & - & Between mi and vhi & $\mathrm{Ai}$ & $\mathrm{mi}$ \\
\hline R3 & Between li and mi & Between vli and mi & - & At least mi & vli \\
\hline R4 & At most li & ni & At most mi & - & li \\
\hline R5 & Between li and vhi & $\mathrm{mi}$ & vhi & hi & - \\
\hline \multicolumn{6}{|c|}{ Expert-2 } \\
\hline R1 & - & At least hi & mi & Between mi and hi & between vli and hi \\
\hline $\mathrm{R} 2$ & At most li & - & hi & Between vhi and ai & $\mathrm{mi}$ \\
\hline R3 & $\mathrm{mi}$ & li & - & At least mi & li \\
\hline R4 & Between li and mi & between ni and vli & at most mi & - & Between li and mi \\
\hline R5 & Between li and vhi & $\mathrm{mi}$ & hi & Between $\mathrm{mi}$ and hi & - \\
\hline
\end{tabular}


Table 3 Enveloped values of experts' opinions

\begin{tabular}{|c|c|c|c|c|c|}
\hline & R1 & $\mathrm{R} 2$ & R3 & $\mathrm{R} 4$ & R5 \\
\hline \multicolumn{6}{|c|}{ Expert-1 } \\
\hline R1 & - & {$[\mathrm{mi}, \mathrm{mi}]$} & {$[\mathrm{mi}, \mathrm{hi}]$} & [hi, ai] & [vli hi] \\
\hline R2 & {$[\mathrm{mi}, \mathrm{mi}]$} & - & [mi, vhi] & [ai,ai] & {$[\mathrm{mi}, \mathrm{mi}]$} \\
\hline R3 & {$[l i, \mathrm{mi}]$} & [vli,mi] & - & {$[\mathrm{mi}, \mathrm{ai}]$} & [vli,vli] \\
\hline R4 & {$[\mathrm{ni}, \mathrm{li}]$} & {$[\mathrm{ni}, \mathrm{ni}]$} & {$[\mathrm{ni}, \mathrm{mi}]$} & - & {$[l i, l i]$} \\
\hline R5 & [li, vhi] & {$[\mathrm{mi}, \mathrm{mi}]$} & [vhi,vhi] & [hi,hi] & - \\
\hline \multicolumn{6}{|c|}{ Expert-2 } \\
\hline R1 & - & [hi, ai] & {$[\mathrm{mi}, \mathrm{mi}]$} & {$[\mathrm{mi}, \mathrm{hi}]$} & [vli, hi] \\
\hline R2 & {$[\mathrm{ni}, \mathrm{li}]$} & - & [hi,hi] & [vhi, ai] & {$[\mathrm{mi}, \mathrm{mi}]$} \\
\hline R3 & {$[\mathrm{mi}, \mathrm{mi}]$} & {$[l i, l i]$} & - & {$[\mathrm{mi}, \mathrm{ai}]$} & {$[\mathrm{li}, \mathrm{li}]$} \\
\hline R4 & {$[\mathrm{li}, \mathrm{mi}]$} & [ni, vli] & [ni,mi] & - & {$[\mathrm{li}, \mathrm{mi}]$} \\
\hline R5 & {$[l i$, vhi] } & {$[\mathrm{mi}, \mathrm{mi}]$} & [hi,hi] & {$[\mathrm{mi}, \mathrm{hi}]$} & - \\
\hline
\end{tabular}

mean operator, which does not allow data loss. To illustrate this process, the following calculation was shown.

Other cells were computed in the same way (Table 4). For R1 to R3, optimistic preferences and pessimistic preferences were calculated using Eq. (1) and Eq. (2):

$$
\begin{aligned}
P_{R 3}^{+} & =\Delta\left(\frac{1}{2}\left(\Delta^{-1}(m i, 3)+\Delta^{-1}(m i, 3)\right)\right. \\
& =\Delta\left(\frac{1}{2}(3+3)\right)=\Delta(3)=(m i,+0.0) \\
P_{R 3}^{-} & =\Delta\left(\frac{1}{2}\left(\Delta^{-1}(h i, 4)+\Delta^{-1}(m i, 3)\right)\right. \\
& =\Delta\left(\frac{1}{2}(4+3)\right)=\Delta(3.5)=(m i,+0.5)
\end{aligned}
$$

From the values of Table 4, interval utilities were calculated (arithmetic mean of each rows of Table 4). After that, interval utilities were computed. Finally, the weights of risk groups were calculated by normalizing the midpoints. According to Table 5, the two most important risk groups are "mental fatigue" and "psychological pressure" followed by "eye related disorders".
Table 5 Interval utilities and the weights of risk groups

\begin{tabular}{llll}
\hline & Interval utilities & Midpoints & Weights \\
\hline R1 & {$[2.75 ; 4.25]$} & 3.50 & 0.233 \\
R2 & {$[3.375 ; 4.0]$} & 3.69 & 0.246 \\
R3 & {$[2.125 ; 3.25]$} & 2.69 & 0.179 \\
R4 & {$[0.75 ; 2.125]$} & 1.43 & 0.095 \\
R5 & {$[3.25 ; 4.125]$} & 3.69 & 0.246 \\
\hline
\end{tabular}

\section{Results}

According to the results, the two most important risk factors were mental fatigue and psychological pressure. Mental fatigue as the principal risk factor was not unexpected owing to the many encounters between humans and machines. However, with respect to psychological pressure, we were unable interpret the results in the same way as the mental fatigue case.. Psychological pressure is a complicated problem, and a more in-depth and detailed investigation is needed. This becomes especially apparent as the relationship between workforce (variety, cycle, skills, uncertainties, exposure, etc.), company (team scheduling, overtime, rush orders, etc.), management (responsibilities, communication, roles, relations, problem solving, etc.) and other organizational influences becomes growing. It was stated that state that such encounters are at the center of many forms of hazards at work, in particular psychological hazards [25]. Engineers and programmers of complex devices sometimes neglect threats like this, which might be the most critical to handle. It should be noted that in terms of regulation and OHS management framework, psychological threats have now been a significant problem.

Moreover, the remaining risk groups are ranked as "eye related disorders", "disorders stemming from the static working position", and "exposure to unknown dangerous particles as a result of cooperation with robots". In addition, interacting with screens will also cause eye health problems. Depending on these results, eye fatigue can be reduced by preventing employees from sitting for a long time with some office activities, which will allow them to
Table 4 Optimistic and pessimistic collective preferences

\begin{tabular}{llllll}
\hline & $\mathrm{R} 1$ & $\mathrm{R} 2$ & $\mathrm{R} 3$ & $\mathrm{R} 4$ & $\mathrm{R}$ \\
\hline $\mathrm{R} 1$ & - & {$[\mathrm{mi},+0.5 ; \mathrm{hi}+0.5]$} & {$[\mathrm{mi},+0.0 ; \mathrm{mi}+0.5]$} & {$[\mathrm{mi}+0.5 ; \mathrm{vhi}+0.0]$} & {$[\mathrm{vli}+0.0 ; \mathrm{hi}+0.0]$} \\
R2 & {$[\mathrm{vli}+0.5 ; \mathrm{li}+0.5]$} & - & {$[\mathrm{mi}+0.5 ; \mathrm{hi}+0.5]$} & {$[\mathrm{vhi}+0.5 ; \mathrm{ai}+0.0]$} & {$[\mathrm{mi}+0.0 ; \mathrm{mi}+0.0]$} \\
R3 & {$[\mathrm{li}+0.5 ; \mathrm{mi}+0.0]$} & {$[\mathrm{vli}+0.5 ; \mathrm{li}+0.5]$} & - & {$[\mathrm{mi}+0.0 ; \mathrm{ai}+0.0]$} & {$[\mathrm{vli}+0.5 ; \mathrm{vli}+0.5]$} \\
R4 & {$[\mathrm{vli}+0.0 ; \mathrm{li}+0.5]$} & {$[\mathrm{ni}+0.0 ; \mathrm{ni}+0.5]$} & {$[\mathrm{ni}+0.0 ; \mathrm{mi}+0.0]$} & - & $[\mathrm{li}+0.0 ; \mathrm{li}+0.5]]$ \\
R5 & {$[\mathrm{li}+0.0 ; \mathrm{vhi}+0.0]$} & {$[\mathrm{mi}+0.0 ; \mathrm{mi}+0.0]$} & {$[\mathrm{hi}+0.5 ; \mathrm{hi}+0.5]$} & {$[\mathrm{mi}+0.5 ; \mathrm{hi}+0.0]$} & - \\
\hline
\end{tabular}


take a break from time to time in the production and office environment. Disorders stemming from the static working position can be prevented by applying job rotation approaches efficiently.

\section{Discussion}

The big challenge confronting Industry 4.0 companies here is the recruitment of current and increasingly wellpotential workers to learn. In the future, there would be a wide number of occupational threats $[26,27]$. Improved connectivity and communication between robots and staff is the cornerstone of Industry 4.0 [28]; however, this does not imply further applications for human-machine coordination but instead innovative methods of exchanging assignments to accomplish complicated operations further efficiently [29-31]. In order to avoid the development of unintended hazards in the manufacturing process, it is important to schedule activities more carefully and explain each participant's limits more thoroughly. In very complex manufacturing settings, the idea of risk management in real time often becomes relevant [32-34]. Artificial intelligence may play an important role in that sense by promoting decisionmaking and thus growing workplace risk because of the complexities of the new world [35, 36]. Fernández and Pérez [37] notice that innovative manufacturing methods will pose new risks for occupational health and safety but that conventional laboratory risk analysis techniques do not seem to be capable of detecting such risks. This study suggests that in order to solve this issue, the latest risk analysis models should be applied, able to track all occupational health and safety threats (conventional and emerging).

\section{Conclusion}

In this study, we have conducted Hesitant Fuzzy AHP technique to investigate new occupational health and safety risks that may arise with the integration of Industry 4.0 in production environments. First of all; we have identified the related risk groups that can arouse with the Industry 4.0. Secondly, we have evaluated the risk groups using Hesitant Fuzzy AHP. Finally, we have given some recommendations based on the gained results to related companies to prevent their employees from the new emerging occupational risks. According to the results, the two most important risk factors were mental fatigue and psychological pressure. The companies, especially on the edge of the transition to Industry 4.0, should consider these two risk groups seriously.
For future research, existing different linguistic scales and MCDM methods can be applied to this MCDM problems, and the results can be compared. At the same time, different risk factors may be investigated and included in this study. In this study, we assumed that there is no connection or internal dependence among the determined risk factors while performing the analysis. Future studies may take into account the fact that these new occupational health and safety risks are dependent on and trigger each other.

\section{Compliance with ethical standards}

Conflict of interest The authors declare that they have no conflict of interest.

\section{References}

1. Sumer B (2018) Impact of Industry 4.0 on occupations and employment in Turkey. Eur Sci J 14(10):1-17

2. Badri A, Boudreau-Trudel B, Souissi AS (2018) Occupational health and safety in the industry 4.0 era: a cause for major concern? Saf Sci 109:403-411

3. Pavón I, Sigcha LF, Arezes PM, Costa N, de Arcas G, LopezNavarro JM. (2018). Wearable technology for occupational risk assessment: Potential avenues for applications. In: Occupational safety and hygiene $\mathrm{Vl}, 447-452$.

4. Leso V, Fontana L, lavicoli I (2018) The occupational health and safety dimension of Industry 4.0. La Med del lavoro 110(5):327-338

5. Romero D, Stahre J, Wuest T, Noran O, Bernus P, Fast-Berglund $\AA$, Gorecky D. (2016) Towards an operator 4.0 typology: a humancentric perspective on the fourth industrial revolution technologies. In: International conference on computers and industrial engineering (CIE46) proceedings

6. Bonekamp L, Sure M (2015) Consequences of Industry 4.0 on human labour and work organisation. J Bus Media Psychol 6(1):33-40

7. Ben-Ner A, Urtasun A (2013) Computerization and skill bifurcation: the role of task complexity in creating skill gains and losses. ILR Rev 66(1):225-267

8. EU-OSHA- European Agency for Safety and Health at Work (2017) Monitoring tehnology: the 21st century's pursuit of well-being?. Available on line at https://osha.europa.eu/en/ tools-and-publications/publications/monitoring-technology -workplace/view. Last accessed 10 Aug 2019

9. Adem A, Çolak A, Dağdeviren M (2018) An integrated model using SWOT analysis and Hesitant fuzzy linguistic term set for evaluation occupational safety risks in life cycle of wind turbine. Saf Sci 106:184-190

10. Dağdeviren M, Yavuz S, Kılınç N (2009) Weapon selection using the AHP and TOPSIS methods under fuzzy environment. Expert Syst Appl 36:8143-8151

11. Dağdeviren $M$, Yüksel I (2008) Developing a fuzzy analytic hierarchy process (AHP) model for behavior-based safety management. Inf Sci 178:1717-1733

12. Rodriguez RM, Martinez L, Herrera F (2012) Hesitant fuzzy linguistic term sets for decision making. IEEE Trans Fuzzy Syst 20(1):109-119 
13. Saaty TL (1980) The analytic hierarchy process. Mcgraw-Hill, New York

14. Zadeh LA (1965) Fuzzy sets. Inf Control 8(3):338-353

15. Gül M. (2018). Application of Pythagorean fuzzy AHP and VIKOR methods in occupational health and safety risk assessment: the case of a gun and rifle barrel external surface oxidation and coloring unit. Int J Occup Saf Ergon, 1-15

16. Yager R (2014) Pythagorean membership grades in multi criteria decision making. IEEE Trans Fuzzy Syst 22(4):958-965

17. Wang CY, Wan L (2018) Type-2 fuzzy implications and fuzzy-valued approximation reasoning. Int J Approx Reason 102:108-122

18. Zhang QL, Liu F, Fan CQ, Xie WH (2018) Fuzzy numbers intuitionistic fuzzy descriptor systems. Inf Sci 469:44-59

19. Zhang X, Xu Z (2017) Hesitant fuzzy multiple criteria decision analysis based on TOPSIS. In: Studies in Fuzziness and Soft Computing, 345

20. Li ZH (2014) An extension of the MULTIMOORA method for multiple criteria group decision making based upon hesitant fuzzy sets. J Appl Math 2:1-16

21. Chen N, Xu Z (2015) Hesitant fuzzy ELECTRE II approach: a new way to handle multi-criteria decision making problems. Inf Sci 292:175-197

22. Zhang N, Wei G (2013) Extension of VIKOR method for decision making problem based on hesitant fuzzy set. Appl Math Model 37:4938-4947

23. Yavuz M, Oztaysi B, Onar SC, Kahraman C (2015) Multi-criteria evaluation of alternative-fuel vehicles via a hierarchical hesitant fuzzy linguistic model. Expert Syst Appl. 42(5):2835-2848

24. Rouyendegh BD, Yilmaz I (2019) 5th International conference on engineering sciences: proceedings of the ICES2019, Sep. 2019, Ankara Yıldırım Beyazıt University, Ankara, Turkey, ISBN: 978-168418-668-6. Adem, A, Çakıt E, Dağdeviren, M., An investigation of the new occupational risks posed by Industry 4.0, 1-3

25. Leka S, Jain A (2010) Health impact of psychosocial hazards at work: an overview. World Health Organization, Geneva, p 136

26. Lorenz M, Rüßmann M, Strack R, Lueth KL, Bolle M (2015) Man and machine in Industry 4.0: how will technology transform the industrial workforce through 2025? The Boston Consulting Group, 22

27. European Commission (2013) Factories of the future-multiannual roadmap for the contractual PPP under Horizon 2020. Prepared by European Factories of the Future Research Association (EFFRA), p 136

28. Bonini M, Prenesti D, Urru A, Echelmeyer W (2015) Towards the full automation of distribution centers. In: 2015 4th IEEE international conference on advanced logistics and transport, IEEE ICALT 7136589. pp 47-52

29. Waschneck B, Altenmüller T, Bauernhansl T, Kyek A (2017) Production scheduling in complex job shops from an industrie 4.0 perspective: a review and challenges in the semiconductor industry. CEUR Workshop Proceedings 1793

30. Christiernin LG, Augustsson S (2016) Interacting with industrial robots: a motionbased interface. In: Proceedings of workshop advanced visual interfaces, pp 310-311

31. Gattullo M, Uva AE, Fiorentino M, Gabbard JL (2015) Legibility in industrial AR: text style, color coding, and illuminance. IEEE Comput Graph Appl 35(2):52-61

32. Podgórski D, Majchrzycka K, Dąbrowska A, Gralewicz G, Okrasa $M$ (2017) Towards a conceptual framework of OSH risk management in smart working environments based on smart PPE, ambient intelligence and the Internet of Things technologies. Int J Occup Safe Ergon 23(1):1-20

33. Niesen T, Houy C, Fettke P, Loos P (2016) Towards an integrative big data analysis framework for data-driven risk management in industry 4.0. In: Proceedings of the annual Hawaii international conference on system sciences, 7427814, pp 5065-5074

34. Malinowski ML, Beling PA, Haimes YY, LaViers A, Marvel JA, Weiss BA (2015) System interdependency modeling in the design of prognostic and health management systems in smart manufacturing. In: Proceedings of the annual conference of the prognostics and health management society, pp 210-222

35. Ahmar, M., 2017. Al can play a big role in smarter decision making. https://www.cxotoday.com/story/ai-can-play-a-big-role-insmarter-decision-making/. Accessed July 18, 2019.

36. Percy, S., 2017. Artificial intelligence: the role of evolution in decision-making. https://www.telegraph.co.uk/business/digit al-leaders/horizons/artificialintelligence-role-of-evolution-indecision-making/. Accessed 18 July 2019

37. Fernández FB, Pérez MÁS (2015) Analysis and modeling of new and emerging occupational risks in the context of advanced manufacturing processes. Procedia Eng 100:115

Publisher's Note Springer Nature remains neutral with regard to jurisdictional claims in published maps and institutional affiliations. 